\title{
Merkel Cell Carcinoma
}

\author{
Wallis S, 'Durham-hall A, Tandon N,' Brotherston TM, 'Shrestha BM' \\ 'Northern General Hospital, Sheffield, United Kingdom.
}

\section{ABSTRACT}

Merkel cell carcinoma (MCC) is a rare but aggressive neuroendocrine tumour of the skin with high rate of local recurrence and distant metastatic potential leading to poor outcomes. Merkel cells are normally found as innervated clusters of cells around hair follicles in the basal layer of the epidermis and are thought to function as touch receptors. Here, we describe a case of MCC in a 71-year-old female and provide an up-to-date review of the literature pertinent to the management of MCC.

Key Words: merkel cell carcinoma, diagnosis, imunohistochemistry, management

\section{INTRODUCTION}

Merkel cells are normally found as innervated clusters of cells around hair follicles in the basal layer of the epidermis and are thought to function as touch receptors. They can also be found as isolated cells in the dermis with no obvious neural connection. Merkel cell carcinoma (MCC) is an uncommon and aggressive primary cutaneous neuroendocrine carcinoma with a high rate of local recurrence and distant metastasis and is considered as the second most deadly form of skin cancer after melanoma, with a mortality rate of as high as 35 percent. In this report, we describe a case of MCC and review the literature pertinent to its management.

\section{CASE REPORT}

A 71-year-old lady was referred to surgical out patients by her general practitioner with a lump on the posterior aspect her right elbow, which was approximately
$2 \mathrm{~cm} \times 1 \mathrm{~cm} \times 1 \mathrm{~cm}$ in dimension and had grown slowly over the past six months. A clinical diagnosis of subcutaneous lipoma was made. She had a significant past medical history, which included autoimmune hepatitis for which she took azathioprine, oesophageal varices, hypothyroidism, ischaemic heart disease and non-insulin dependent diabetes mellitus.

As the skin overlying the lump was noted to be slightly darker than rest of the surrounding skin and also had firm consistency, it was excised under local anaesthetic on a priority basis. At operation, the lump had an illdefined edge and merged with the surrounding fat, hence was excised in multiple fragments. Microscopically, there was fibro-fatty tissue

diffusely infiltrated by a neoplasm comprising small, hyperchromatic cells with dusty chromatin, nuclear moulding, and nuclear smudging with minimal amount

Correspondence:

B M Shrestha,

Department of General Surgery

Northern General Hospital

Herries Road, Sheffield, S5 7AU, UK.

Email: shresthabm@doctors.net.uk 
of amphophillic cytoplasm in keeping with neuro-endocrine carcinoma (Figure 1 and 2). Immunohistochemistry showed strong dot positivity for pancytokeratins as seen in neuro-endocrine carcinoma (Figure 3), dot-like positivity for cytokeratin - 20 (CK20) which is specific for MCC of skin (Figure 4). There was positive staining with CD56 indicating presence of neural cell adhesion molecule (Figure 5).

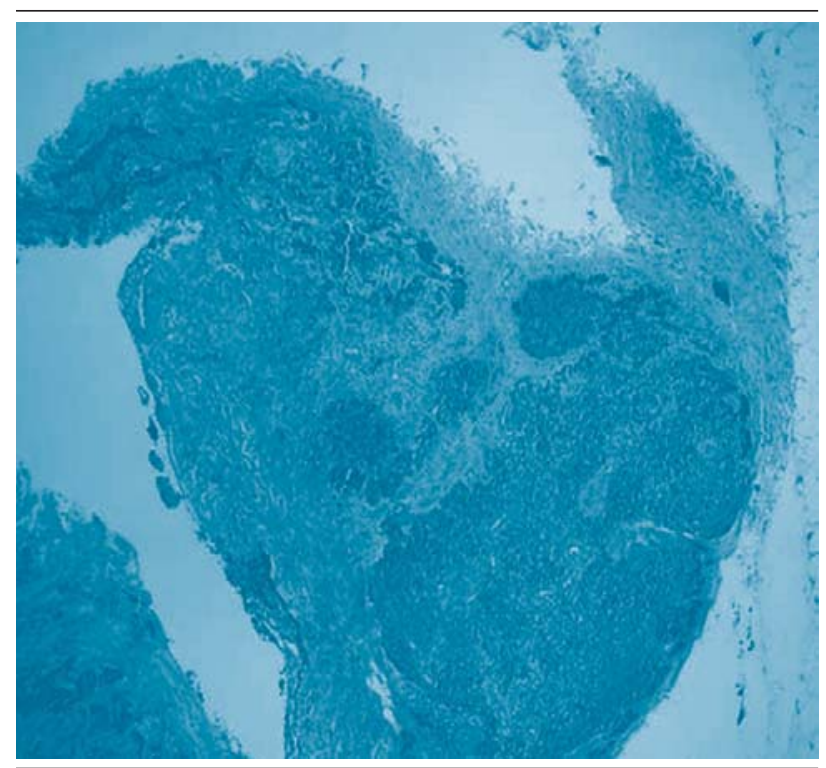

Figure 1. Section stained with haematoxylin and eosin (x40)

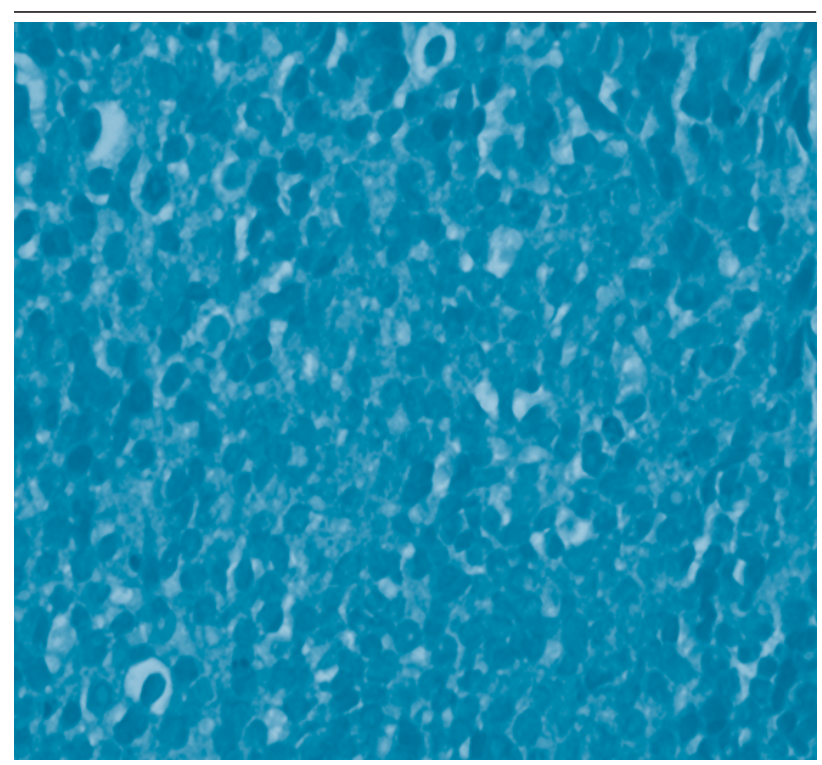

Figure 2. Section stained with haematoxylin and eosin (x200

The definitive diagnosis of MCC of the skin in this case was made clinically by excluding metastatic neuroendocrine carcinoma. Most MCC present in the dermis whereas in this patient this was subcutaneous. Staging of the disease was carried out by doing a contrast-

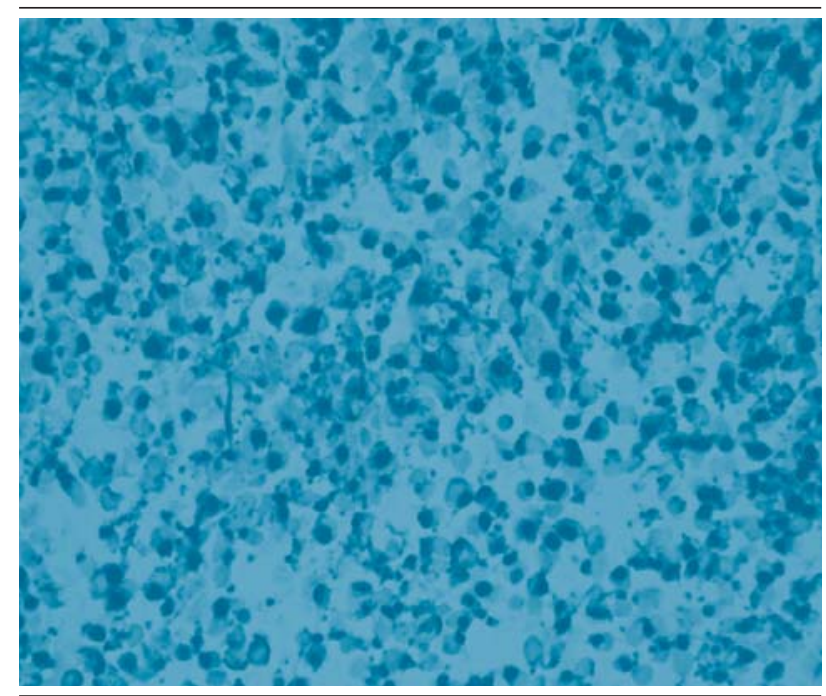

Figure 3. Dot-like positivity with pancytokeratin

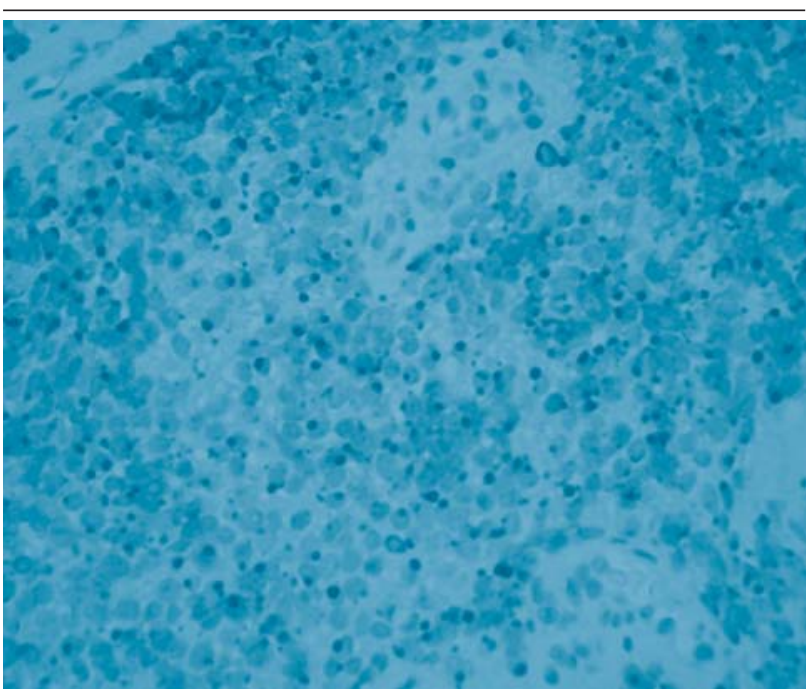

Figure 4. Dot-like positivity with pancytokeratin



Figure 5. Membrane positivity with CD56 (neural cell adhesion molecule) 
enhanced computerised tomographic (CT) scan of the thorax and abdomen, which revealed bulky right axillary lymph nodes and a further node in the anterior chest wall infero-medial to the breast. There was no evidence of bony or intra-abdominal metastases. Following discussion in the dermatology multi-disciplinary meeting, the patient underwent further wide excision of the primary lesion, block dissection of the right axilla and excision of two more large lymph nodes from the medial aspect of the right arm. In view of several existing co-morbidities, she was not considered for adjuvant chemo- or radiotherapy.

\section{DISCUSSION}

Frederick Sigmund Merkel, a German histopathologist, first discovered the Merkel Cell in 1875. Cyril Toker first described Merkel cell carcinoma in 1972 although it was initially named trabecular carcinoma of the skin, presumed to be of sweat gland origin. Subsequent electron microscopic studies identified dense-core neuroendocrine granules within the tumour cells which demonstrated their origin from Merkel cells. ${ }^{5,6}$

The aetiology of MCC is not clearly understood. However, the distribution of lesions has been found to be more common in the extremities and in sun-exposed areas, such as the head and neck in elderly patients. State of immune-suppression, such as in AIDS and organ transplantation, increases the risk of MCC. More lately, polyoma virus is found to be implicated in the pathogenesis of MCC.

Clinically, MCC may present as a firm shiny lump on or within the skin and may be coloured (pink, blue or red). There are no specific clinical diagnostic features, however, suggestive characteristics include: lack of tenderness, rapid expansion, immune suppression, older than 50 and in sites exposed to UV light. Whilst MCC is more common in the extremities, head and neck, it has also been reported as presenting as metastases in lymph nodes with unknown primary. There may be presence of intransit metastases as in cases of malignant melanoma. The histology of MCC shows small round blue cell tumours with sparse cytoplasm and medium-sized nuclei on haematoxylin-eosin staining. There are three subtypes of MCC described. Trabecular subtype has cells arranged in organoid clusters. Intermediate subtype is most common and more aggressive than trabecular and shows a solid diffuse growth pattern. The small cell subtype appears as sheets and clusters of cells and mimics the behaviour of other small cell tumours.

MCC shares features with other malignancies including basal cell carcinoma and small cell carcinoma of the lung. Immunocytochemistry can be used in order to differentiate MCC from other malignancies. Cytokeratin and neuron- specific enolase are the most useful markers. The presence of lymphovascular invasion and infiltration into adjacent tissues indicates aggressive behaviour of the tumour. A computerised tomographic scan of thorax and abdomen is essential for staging. In addition to TNM classification, a commonly used staging system is shown in Table 1 .

The treatment of MCC depends on the stage of the disease. A comprehensive guidelines on the management of MCC is available on the National Cancer Network of the United States of America. Most authors recommend wide local excision of the primary lesion and regional lymph node resection, if lymph nodes are palpable, followed by $x$-irradiation of both sites. The role of elective lymph node resection in the absence of clinically-positive nodes has been controversial in the past. More lately, as in breast cancer, sentinel node biopsy is routinely practiced. MCC has been shown to be radiosensitive and adjuvant radiotherapy has a recognised role in the treatment as this gives better loco-regional control.. Trials have shown improved disease-free survival in patients who had radiotherapy in addition to surgery compared to those who had surgery alone.

Toxicity is the key factor in any regimen, as the patients are usually elderly and likely to have other significant medical problems. Because of rarity of MCC, evidencebased regimens are difficult to establish. Platinum-based chemotherapy or doxorubicin have been tried as an adjuvant therapy for advanced disease, with favourable response. As MCC is a relatively rare malignancy there is a lack of prospective controlled trials to analyse the treatment outcomes. A multicenter study in the United States to evaluate the safety and efficacy of the combination of fluorouracil, leucovorin calcium, and oxaliplatin (FOLFOX) with bevacizumab in patients with advanced neuroendocrine tumours is in progress. In vitro studies of MCC, interferon-alpha is shown to activate caspase-3, an enzyme involved in inducing apoptosis leading to breakdown of DNA strands and fragmentation of nuclei, hence a potential agent for the treatment of MCC

The clinical outcome of MCC following treatment in a retrospective study of 156 patients with MCC, showed an overall 5 -year survival rate of $67.5 \%$. In addition to the stage of the disease, tumour thickness (depth of tumour invasion), the presence of lympho-vascular invasion and tumour growth pattern (nodular circumscribed vs infiltrative) had significant influence on the long-term prognosis. Local recurrence develops in $26-44 \%$ of patients despite therapy. Up to three-fourths of patients eventually develop regional nodal metastases with distant metastases occurring in one-third of all patients. 
MCC is an aggressive cancer with poor prognosis, which requires a multi-disciplinary approach through a team consisting of surgeon, oncologist, radiotherapist and rehabilitation for optimum patient outcomes. Because of its rarity, it is paramount to record cases in a central registry and embark on multicentre studies for establishing robust treatment protocols.

\section{REFERENCES}

1. Tai P. Merkel cell cancer: update on biology and treatment. Curr Opin Oncol. 2008 Mar;20(2):196-200.

2. Veness MJ, Palme CE, Morgan GJ. Merkel cell carcinoma: a review of management. Curr Opin Otolaryngol Head Neck Surg. 2008 Apr;16(2):170-4.

3. Ely H, Pascucci A. Merkel cell carcinoma: treatment with bleomycin. Dermatol Online J. 2008 Sep 15;14(9):3.

4. Toker C. Trabecular carcinoma of the skin. Arch Dermatol. 1972 Jan;105(1):107-10.

5. Tang CK, Toker C. Trabecular carcinoma of the skin: an ultrastructural study. Cancer. 1978 Nov;42(5):2311-21.

6. Gould VE, Dardi LE, Memoli VA, Johannessen JV. Neuroendocrine carcinomas of the skin: light microscopic, ultrastructural, and immunohistochemical analysis. Ultrastruct Pathol. 1980 Oct-Dec;1(4):499-509.

7. Akhtar S, Oza KK, Wright J. Merkel cell carcinoma: report of 10 cases and review of the literature. J Am Acad Dermatol. 2000 Nov;43(5 Pt 1):755-67.

8. Garneski KM, Warcola AH, Feng Q, Kiviat NB, Leonard JH, Nghiem P. Merkel cell polyomavirus is more frequently present in North American than Australian Merkel cell carcinoma tumors. J Invest Dermatol. 2009 Jan;129(1):246-8.

9. Heath M, Jaimes N, Lemos B, Mostaghimi A, Wang LC, Peñas $\mathrm{PF}$ et al. Clinical characteristics of Merkel cell carcinoma at diagnosis in 195 patients: the AEIOU features. J Am Acad Dermatol. 2008 Mar;58(3):375-81.

10. Nazarian Y, Shalmon B, Horowitz Z, Bedrin L, Pfeffer MR, Talmi YP. Merkel cell carcinoma of unknown primary site. J Laryngol Otol. 2007 Apr;121(4):e1.

11. Gupta AS, Heinzman S, Levine EA. Successful treatment of intransit metastases from Merkel's cell carcinoma with isolated hyperthermic limb perfusion. South Med J. 1998 Mar;91(3):28992

12. Koljonen V. Merkel cell carcinoma. World J Surg Oncol. 2006:4;7.

13. Ball NJ, Tanhuanco-Kho G. Merkel cell carcinoma frequently shows histologic features of basal cell carcinoma: a study of 30 cases. J Cutan Pathol. 2007:34:612-9.

14. Schmidt U, Muller U, Metz KA, Leder LD. Cytokeratin and neurofilament protein staining in Merkel cell carcinoma of the small cell type and small cell carcinoma of the lung. Am J Dermatopathol. 1998:20:346-51.

15. Beer TW, Ng LB, Murray K. Mast cells have prognostic value in Merkel cell carcinoma. Am J Dermatopathol 2008:30;27-30.
16. Haag ML, Glass LF, Fenske NA. Merkel cell carcinoma. Diagnosis and treatment. Dermatol Surg 1995:21;669-83.

17. NCCN Clinical practice guidelines in oncology. [online] [cited o n $\quad 2009$ A $\quad$ A a ilable from : U R L : http://www.nccn.org/professionals/physician_gls/f_guide lines.asp

18. Eng TY, Boersma MG, Fuller CD, Goytia V, Jones WE 3rd, Joyner $\mathrm{M}$ et al. A comprehensive review of the treatment of Merkel cell carcinoma. Am J Clin Oncol. 2007 Dec;30(6):62436.

19. Clark JR, Veness MJ, Gilbert R, O'Brien CJ, Gullane PJ. Merkel cell carcinoma of the head and neck: is adjuvant radiotherapy necessary? Head Neck 2007:29;249-57.

20. Shnayder Y, Weed DT, Arnold DJ, Gomez-Fernandez C, Bared A, Goodwin WJ et al. Management of the neck in Merkel cell carcinoma of the head and neck: University of Miami experience. Head Neck. 2008 Dec;30(12):1559-65.

21. Lawenda BD, Arnold MG, Tokarz VA, Silverstein JR, Busse PM, McIntyre JF et al. Analysis of radiation therapy for the control of Merkel cell carcinoma of the head and neck based on 36 cases and a literature review. Ear Nose Throat J. 2008 Nov;87(11):634-43.

22. Raj Pandey K. Adjuvant radiotherapy improves survival in MCC of skin. Lancet Oncol. 2007:8;76.

23. Wobser M, Kürzinger N, Ugurel S, Bröcker EB, Becker JC. Therapy of metastasized Merkel cell carcinoma with liposomal doxorubicin in combination with radiotherapy. J Dtsch Dermatol Ges. 2009 Jun;7(6):521-5.

24. Henness S, Vereecken P. Management of Merkel tumours: an evidence-based review. Curr Opin Oncol 2008:20;280-6.

25. Phase I/II Pilot Study of Fluorouracil, Leucovorin Calcium, and Oxaliplatin (FOLFOX) With Bevacizumab in Patients With Advanced Neuroendocrine Tumors. National Cancer Insitute, US NIH, 2009. Available from: URL: http://www.cancer.gov/clinicaltrials/CALGB-C80405

26. Krasagakis K, Krüger-Krasagakis S, Tzanakakis GN, Darivianaki K, Stathopoulos EN, Tosca AD. Interferon-alpha inhibits proliferation and induces apoptosis of merkel cell carcinoma in vitro. Cancer Invest. 2008 Jul;26(6):562-8.

27. Andea AA, Coit DG, Amin B, Busam KJ. Merkel cell carcinoma: histologic features and prognosis. Cancer. 2008 Nov 1;113(9):254958. 